\title{
PRACTICE
}

\section{Research Opportunities for High School Students at the Ocean Research College Academy}

Ardi Kveven, Everett Community College

\begin{abstract}
Providing opportunities for students to engage in undergraduate research is well supported as a high-impact educational practice. Shifting research experience earlier in the undergraduate career provides opportunities for more students to yield gains (both personal and professional) earlier in their career. At the Ocean Research College Academy (ORCA), undergraduate research starts when students are in their third year of high school. As part of a dual credit/enrollment program in Washington state, students earn an associate of arts and science degree when they graduate from high school. With 17 years of data and more than 500 graduates who have compelling matriculation rates and baccalaureate degree attainment, ORCA provides a model for program and course-based undergraduate research replicable by others.
\end{abstract}

Keywords: community colleges, course-based undergraduate research, dual enrollment, high school, mentoring, oceanography

doi: $10.18833 /$ spur/4/3/13

One of the most exciting attributes of providing research experiences for students is the voyage of discovery resulting from their engagement. The research process reveals discoveries not only about the science but about the students as well. For example, students are participating in the emerging trend of studying scat (fecal matter) as a noninvasive means to determine diet, population, disease, and genetics. Sieving and filtering river otter scat samples and teasing out the otoliths (ear bones) of prey items reveals not only fish species but also the presence of soft-shelled crab, eye lenses of fish, microplastics and feathers. Students learn attention to detail, persistence, resiliency, lab and data management skills, networking, and the ability to tolerate certain smells. Although this type of research may be most typical of fourth-year undergraduates or graduate students, it was actually conducted by students in their last year of high school as part of a dual-credit program paired with earning an associate's degree at a community college in Washington state. This is just one example of student research at the Ocean Research College Academy (ORCA) at Everett Community College over the past 17 years.

\section{Dual Enrollment}

Engaging students earlier in research and facilitating college attendance has tremendous potential to increase persistence in STEM fields, particularly for underserved students. Dual-enrollment programs (in which students earn high school and college credit simultaneously) have proliferated in community colleges in the last 20 years. Community colleges in Washington state offer multiple dual transcription opportunities for students. The two largest programs, College in the High School (CHS) and Running Start, vary in where the course is taught and by whom (College in the High School is taught in high schools by high school instructors with students paying tuition, and Running Start is taught at colleges by college faculty with tuition covered by the state and students paying course fees). Although the CHS opportunity is often another avenue for high-achieving students with the ability to pay, Running Start could be further utilized by underserved populations (Fink, Jenkins, and Yanagiura 2017). Both programs represent ways for middle-income families to save money, and the momentum built by students with a college transcript carries through to university regardless of whether Running Start students in Washington state enroll at the sponsoring community college or a university. 
Everett Community College pioneered the Running Start Program 30 years ago and operates the largest College in the High School program in the state. The majority of credits earned by students is often in social science and humanities (due in part to the need to fulfill remaining high school graduation requirements), and only 11 percent of enrolled students completed the associate of arts and sciences degree. Now more than ever, dual-enrollment programs are recommended to accelerate time to degree completion and reduce costs for families, students, and the state. According to research on dual credit, students with dual credit go on to college and earn postsecondary degrees earlier than students without dual credit (Shapiro et al. 2016). There are limited examples, however, that use undergraduate research in the context of this dual-enrollment educational model.

\section{ORCA Launch}

After 14 years of teaching high school students, Kveven combined reflections on effective STEM education that is discovery- and research-based with the emphasis on building a community of learners (Kveven and Searle 2008). To provide greater access to underserved students in STEM (women, students of color, low-income students, and first-generation college attendees), Kveven received a grant from the Bill and Melinda Gates Foundation, which invested \$3.36 million in small school programs in Washington state in 2003 based on research from How People Learn (National Research Council 2000).

Kveven experienced how central relationships were to student success, particularly for underserved students. Thus, the research-centric ORCA began with a small community of active, responsible, and inquisitive learners, engaging them in pioneering efforts to study the local estuary and share the results with the local community. ORCA planned a two-year program to meet both high school graduation requirements and associate degree requirements. Recent research emphasizes the influence of kindness and community on broadening participation in STEM (Estrada, Eroy-Reveles, and Matsui 2018). This community emphasis at ORCA aligned with high-impact practices (Kuh 2008). ORCA now admits 60 new students annually to a full-time, two-year program that incorporates most of the high-impact practices, starting with a first-year seminar based in the community and undergraduate research conducted as part of a learning community.

\section{Research Experiences at ORCA}

With startup funding and planning time provided by the Bill and Melinda Gates Foundation grant, ORCA designed student learning outcomes around active engagement in research centered on the local estuary. The seminal project that drove student research was developed by Kveven and founding faculty members to engage students in the core academic content while they studied the local marine environment in the field. This one-year course/program undergraduate research experience involves first-year students collecting and analyzing a suite of oceanographic parameters to monitor marine waters and health conditions - a process similar to what is measured by state agencies. By adapting some of the long-term monitoring of temperature, salinity, and dissolved oxygen and $\mathrm{pH}$ for the local region, course objectives in Oceanography 101 are met. Expanding research to include biota (plankton, fecal coliform bacteria, seabirds, and marine mammals) incorporated learning outcomes for the Marine Biology 130 course. This project, called the State of Possession Sound (SOPS; see Figure 1), blends course learning objectives in science and mathematics coursework with research skill development and collaborative research (Kveven and Searle 2013). Students apply statistical methods from their mathematics courses to collect and analyze their data. The establishment of longitudinal data provides opportunities for students to ask broad questions about the ecosystem, as they continue to contribute to the long-term database. Most important, however, the program documents the capabilities of high school students when they have the opportunity to do research in a rich, mentored environment. Evolving collaborations include academic institutions, but local and state governmental agencies as well as a local environmental consulting firm have thus far provided the greatest support for the students.

Timely investments and grants supported students in their second year so they could continue to enhance and expand on their first-year research. Support from the National Science Foundation (NSF) from four funding initiatives provided time and support for students to dive deeper into research through a dedicated student research lab, supplies, equipment, faculty time, technical support, student stipends, and a research vessel. The Community College Undergraduate Research Initiative (CCURI) was catalytic in providing sponsored travel so that students could present their research at professional events and inspired ORCA to create the Possession Sound Student Showcase and Talks, a showcase event for the local community. Teaching students how to tell a story and to establish networks are tremendous outcomes from this annual event (see Figure 2). The graph highlights a significant increase of student engagement in original research in the 2014-2020 period, where students build upon the questions they asked during the first year through SOPS and have the resources in place through grant funding and community connections.

CCURI and NSF grants facilitated sharing the ORCA origin story to continue to garner support for students' work. Another giant leap forward came when the NSF program officer from the student research laboratory encouraged ORCA to submit a proposal for a research vessel. This proposal was funded through NSF's Field Stations and Marine Labs, and for more than six years, ORCA has operated its own research vessel: the custom-built Phocoena (see Figure 
FIGURE 1. The Region in the Pacific Northwest Known as the Salish Sea, Located North of Seattle

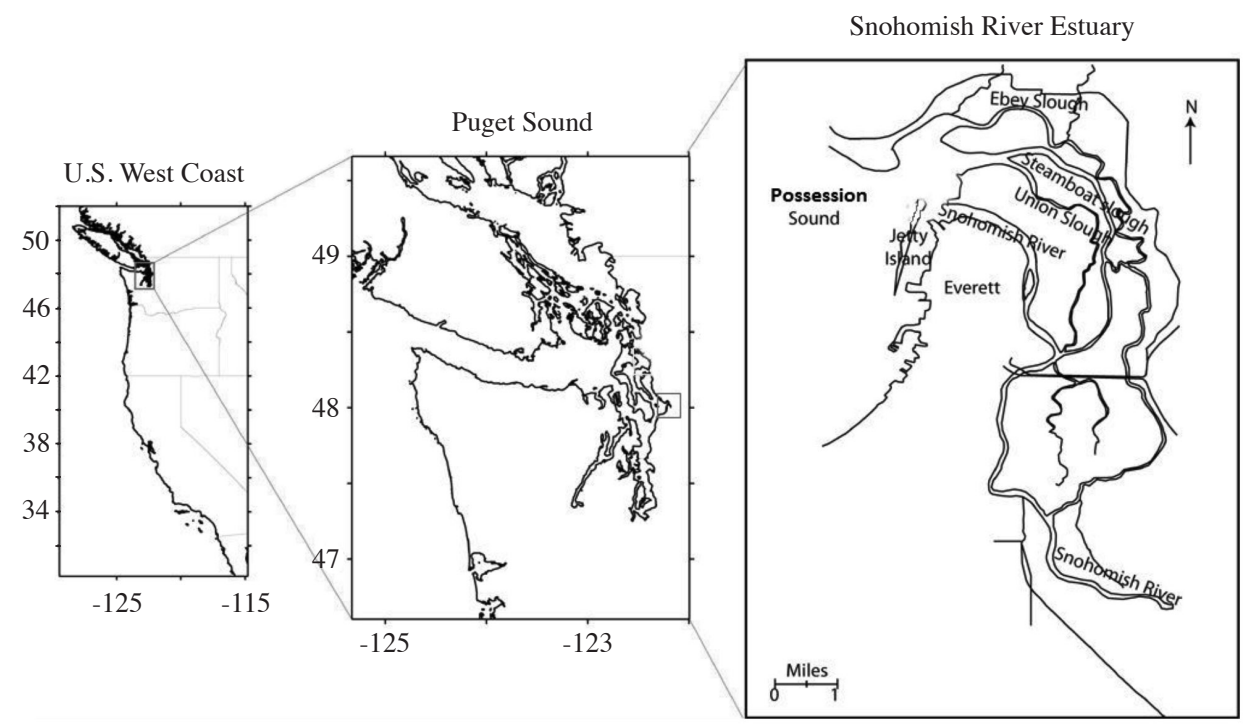

Note: The maps provide details on Possession Sound, the study location for the State of Possession Sound Project (SOPS).

FIGURE 2. Students Engaging in Original Research at ORCA and Presenting Their Work at Symposia

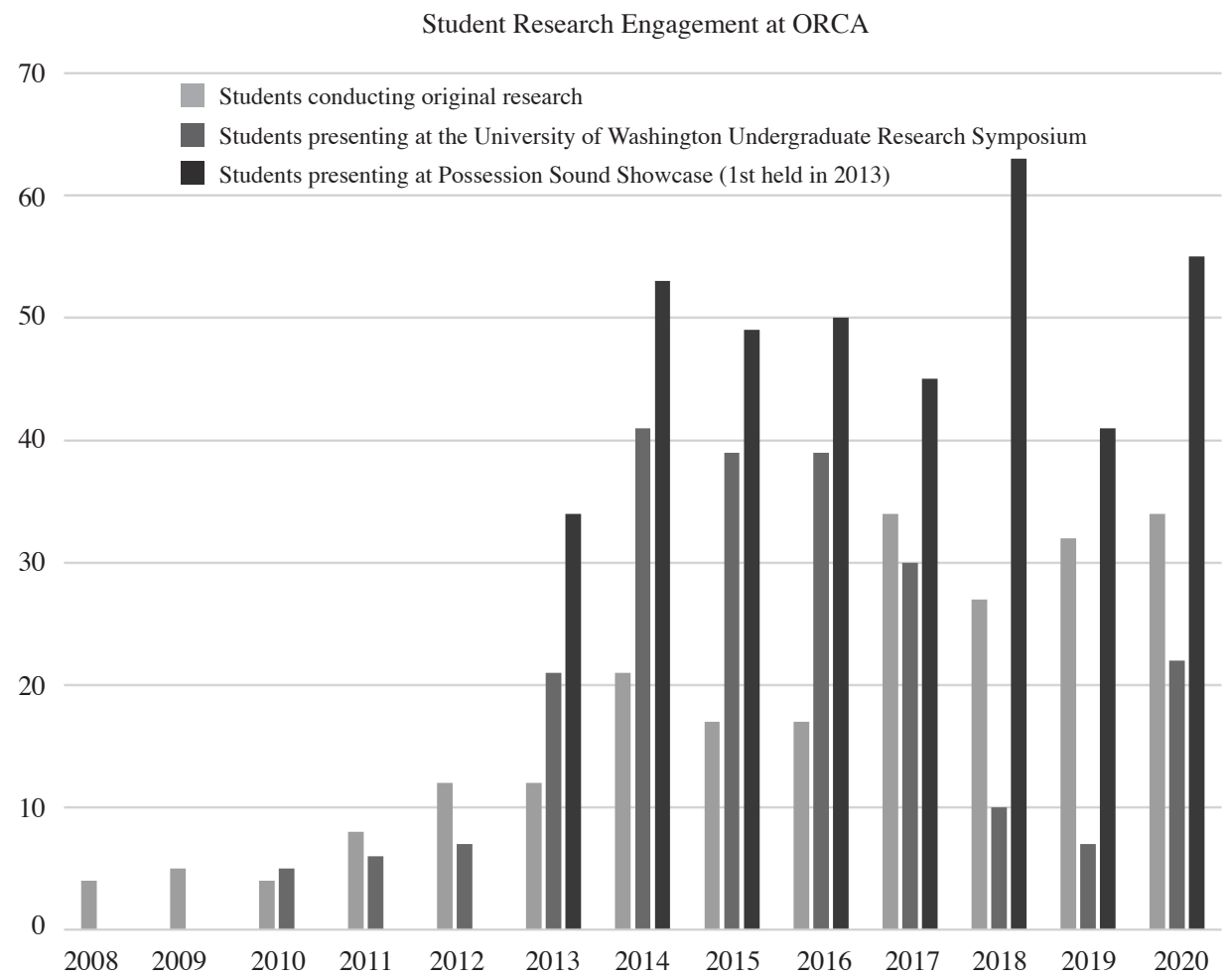

3). This research vessel transformed student research opportunities, as the program was no longer confined to a ferry schedule with a limited sampling route and could work in shallow areas for as long as the students needed (Kveven 2016). This capability continues to enhance the quality and depth of student research questions. More than 34 ORCA students have presented at scientific conferences, predominantly at the Salish Sea Conference, with the following sample research titles:

- Ecosystem Legacy Lead Isotopic Signature in Riverine Sediments in Everett, Washington

42 Scholarship and Practice of Undergraduate Research 
FIGURE 3. Custom-Built Research Vessel Phocoena (Funded by NSF) on the Waters of Possession Sound with Student Researchers and Author/Captain Ardi Kveven

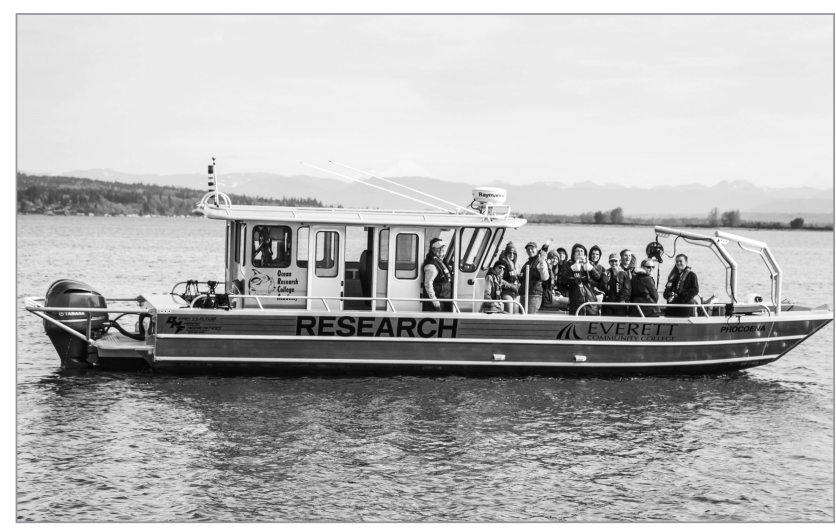

- Patterns of Heavy Metal Concentration and Distribution in Sediment and Marine Invertebrates

- Effects of Tidal Fluctuations and Current Speed on Variations in Temperature, Salinity, and Dissolved Oxygen in the Snohomish River Estuarine System

- Determination of Tidal Influence on River Otters in Estuarine Systems

- Silicate as a Limiting Nutrient to Diatom Growth in Possession Sound

- Eelgrass Distribution in Possession Sound

- Correlation between Anthropogenic Influence and Microplastic Concentration in Possession Sound

- Plankton Density and Larval Fish Abundance in Possession Sound, Washington

One unique attribute of the type of student-driven original research is that it is not apprentice-type work, where the students participate in an offshoot of the principal investigator's work. These wide-ranging questions put each student in charge, and all instructors support students. The mathematics instructor helps students with visual representation of data and data analysis, often using statistical tools, whereas English instructors support the writing of the capstone research paper. Local scientists provide support and inspiration for students as they develop a wide range of skills that are transferable to any discipline. The previously mentioned student projects represent a wide range of eventual university degrees earned by these researchers. One student is in medical school, another is in veterinary school, one graduated with bachelor's and master's degrees in biochemistry, one double majored in psychology and art, one majored in bioengineering, one graduated in forestry, and another earned a double degree in oceanography and nursing.

\section{Program Outcomes}

The large increase in student engagement in original research in their second year of the program comes from grant support providing deliberate time and focus (see Figure 2). The ebb and flow in participation at the University of Washington Undergraduate Research Symposium represent timing and an emphasis on presenting at the Possession Sound Student Showcase and Talks (ORCA n.d.a).

Students have been active participants in providing feedback. Students are in the program for two years, providing qualitative feedback on their experience at the end of year 1 and in the quarter before they graduate. Survey tools have evolved over time from internally developed reflection questions to questions from the Undergraduate Research Student Self-Assessment Survey (URRSA). Faculty review this feedback annually, reflecting on the student experience and using the feedback to enhance the program. Key takeaways from the student narrative include (via self-report):

- Creating curiosity and comfort with asking questions

- Recognizing and appreciating support from faculty and peers

- Developing enhanced skills in working in teams

- Analyzing data

- Building scientific writing skills

- Networking

- Achieving heightened confidence

- Acquiring awareness of the process and nature of science

- Applying learning from the program across disciplines

- Wishing for more boat or field time

\section{Student Outcomes}

Since the program's inception in 2003, 86 percent of enrolled students have earned the associate of arts and science (AAS) degree along with their high school diploma as part of the two-year program. The Washington statewide average of AAS degree attainment is 23 percent in three years. Nearly 66 percent of ORCA graduates pursue and earn STEM university degrees. The historically underserved demographics in STEM include 70 percent female enrollment, and more than 33 percent of graduates include students of color, low-income students, and firstgeneration college students.

Now that a large percentage of ORCA graduates have completed baccalaureate degrees, tracking alumni in the National Student Clearinghouse data is underway. The Institutional Research Office at EvCC provided the following numbers available through the National Student Clearinghouse. Table 1 highlights that 73 percent of ORCA graduates have earned a bachelor's degree. Part of the lag of baccalaureate degree earners could be the amount of time needed for students to earn university degrees. Additionally, finances play a role in time to degree. Continued tracking as each cohort at ORCA advances to university will be ongoing. It would be ideal to capture more of the student gains from the program that last beyond their enrollment. 
TABLE 1. National Student Clearinghouse Data of ORCA Graduates and University Degrees Earned

\begin{tabular}{|c|c|c|}
\hline Degrees earned in the period 2005-2016 & Number & Percentage \\
\hline Total ORCA graduates & 397 & - \\
\hline ORCA graduates earning a bachelor's degree & 290 & - \\
\hline \% ORCA graduates earning a bachelor's degree & - & $73 \%$ \\
\hline Master's degrees earned by ORCA graduates & 46 & - \\
\hline$\%$ Master's degrees earned by ORCA graduates & - & $12 \%$ \\
\hline Doctoral degrees earned by ORCA graduates & 15 & - \\
\hline$\%$ Doctoral degrees (includes MD, DVM, PhD, and Pharm D) & - & $4 \%$ \\
\hline
\end{tabular}

Due to NSF GEOPAths funding, an external evaluator has also monitored student outcomes in context of the Undergraduate Research Student Self-Assessment Survey (URSSA; Weston and Laursen 2017). Tracking student engagement over time includes the following metrics with three years of participants $(n=34)$. Figure 4 represents the gains made by students in data management (100 percent reported "great gain"), visual representation (91 percent reported "great gain," 9 percent "good gain") and statistical tools (36 percent reported "great gain," 45 percent "good gain").

Each year, ORCA graduates matriculate at local, national, and international universities, where they collectively receive between $\$ 200,000$ to $\$ 500,000$ in annual scholarship support to pursue their work at baccalaureate institutions. There have been five ORCA students who have received support from the NOAA Hollings Scholar Award. ORCA alumni have earned NASA Space Grant awards, National Merit Finalist distinction, NSF Graduate Fellowships, the NOAA Nancy Foster Graduate Fellowship, and thousands of dollars of local scholarship support.

The largest NSF grant to date is an IUSE GEOPAths Award, which provides summer research opportunities for students halfway through the ORCA program. The outcomes of this grant include connecting high school students to a wide variety of geoscientists to increase their awareness of geoscience careers, build mentoring relationships to increase the number of underserved students in STEM fields, and facilitate student use of big data as they increase their understanding of the local estuary. Students develop exciting original research projects with mentoring and network support and include cutting-edge sampling in the estuary. For example, two students who were interested in engineering engaged with a program partner on a vertical profiling project from the ORCA's research vessel. Given the pycnocline (density gradient) movement due to tidal exchange and river flow, the students envisioned horizontal profiling as the boat moved through the water at 18 knots. With another collaborator (and dedicated research time due to the GEOPAths grant), these students participated in the design, welding, and fabrication of a device that pumped water over a probe to monitor the parameters and create a geospatial map of the data taken every quarter of a second. One of these students received a NASA Space Grant scholarship, and another is now studying at the University of Munich.

The validation provided by the multiple investments by NSF and the invitation to share ORCA's work while emphasizing these student demographics is encouraging and provides further motivation to target this emerging population of potential researchers and adapt the strategies used successfully for nearly two decades.

\section{Recommendations and Lessons Learned}

The following advice can be offered to aid in transferability of the ORCA experience to other institutions:

- Find the focus. Due to ORCA's location, the program's focus is on marine/estuarine dynamics. However, any regional focus that is studied by a state or local agency is ripe for students to add to the data and network within the community. It was unknown 15 years ago that temperature changes would drive massive deaths of sea stars on the Pacific coast and be evident in the local estuary. Ultimately, the focus is not the elements that drive the work but rather the process of doing the work, evidenced by this student quote: "From experiencing research firsthand, I ask more questions about everything than I used to without even realizing it." The graduates go on to many fields, from medicine to political science, and the skills they develop from research are transferable to any discipline.

- Secure funding. Connect to the institution's grants office. In addition to the NSF awards, ORCA has received small local grants that support the deployment of real-time instrumentation (ORCA n.d.b). 
FIGURE 4. URRSA Responses to GEOPAths Grant Outcomes Over Three Years

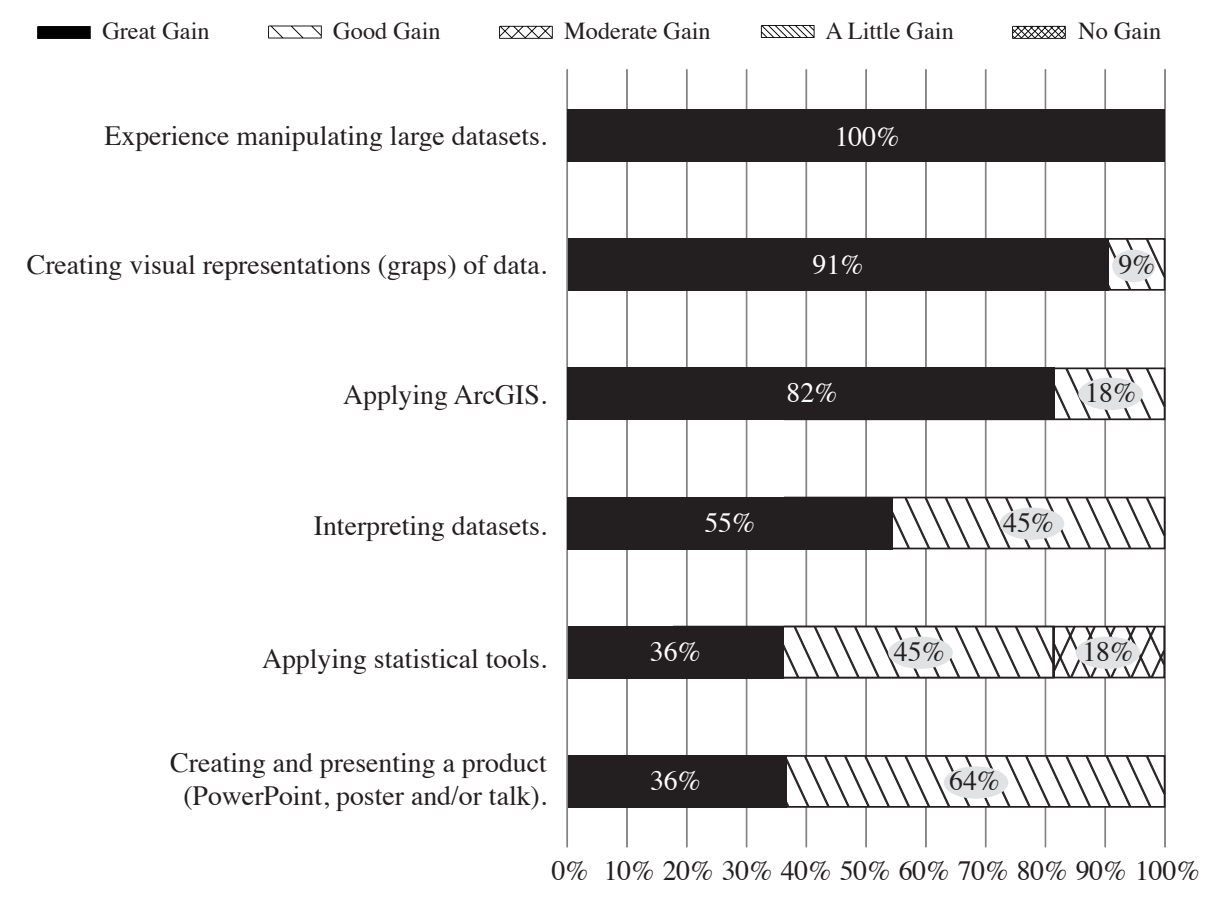

Note: URSSA = Undergraduate Research Student Self-Assessment Survey. Students were asked, "How much did you gain in the following areas as a result of your most recent research experience?" $(n=34)$. Moderate to great gains on all outcomes were reported by all students.

Engage in dialogue with institutional administrators and connect funding to student outcomes by inviting administrators to observe student work. Once the Gates Foundation's start-up grant ended, the college administration agreed to allocate the student enrollment full-time equivalent revenue directly to the ORCA program as the operating budget. Now that many graduates are gainfully employed, there are several who have made financial contributions to new research initiatives.

- Embrace failure. It is important to discuss research failures with students, so they understand that learning can occur from failure and that sometimes the search for the "right" answer may be a long and multifaceted process. Much of the research in science does not support the hypothesis, so providing opportunities for emerging scientists to embrace failure and develop problem-solving skills coupled with resiliency is a lifelong skill.

- Find collaborators. Powerful programs are about the students, faculty, and others who choose to be a part of them. Find out what dual enrollment programs are offered in the institution's region and connect to local high schools, particularly to college/career counselors. Kveven and Searle (2013) have written about the structure of a two-year, cohort-based program that integrates core academic disciplines in the humanities, natural sciences, and social sciences, and committed faculty are at the core of the program's active learning, relationship building, and connection to place that contributes to student retention.

- Solicit essential feedback. In the early years, students were surveyed every quarter about their experience, which provided valuable feedback to mentors. It is also extremely valuable for mentors to share their response to the feedback with students, as it builds trust that their perspectives matter. Students are now surveyed annually via standardized surveys such as URSSA (Weston and Laursen 2017) in addition to the in-house surveys.

This student quote below embodies the legacy of the ORCA program, and asking students to engage in reflection and think deliberately about their learning is a rich part of the process. This passion for connecting students to the science of where they live and engaging them in the study has been tremendously rewarding and can be replicated by other committed, passionate educators.

Words cannot express how ORCA has impacted my life. Over the past two years, I have not only grown as a learner, but as a person. My life would not be the same without this experience. I think of the world as a scientist and a writer now. I am not afraid to ask questions 
and find my own answers. With these skills I know that I can do anything. The academic and personal support provided at ORCA was instrumental, and what I have learned at ORCA will impact me for the rest of my life.

\section{Acknowledgments}

ORCA has been supported by the following grants:

- Bill and Melinda Gates Foundation Grant (2003)

- National Science Foundation ARRA ARI-R2 0963104 (2010)

- National Science Foundation IUSE: CCURI Partner Institution 1118679 and 1524353 (2012)

- National Science Foundation IUSE: FSML 1318552 (2013)

- Port of Everett Support for Water Testing Ongoing through 2020 (2014)

- National Oceanic and Atmospheric Administration Funding for Larval Fish Study (2015)

- National Science Foundation IUSE:GEOPAths 1801658 (2018)

- Grants from a local credit union, nonprofit organizations, and ORCA alumni (2019-2021)

\section{References}

Estrada, Mica, Alegra Eroy-Reveles, and John Matsui. 2018 "The Influence of Affirming Kindness and Community on Broadening Participation in STEM Career Pathways." Social Issues Policy Review 12(1): 258-297. doi: 10.1111/sipr.12046

Fink, John, Davis Jenkins, and Takeshi Yanagiura. 2017. "What Happens to Students Who Take Community College 'Dual Enrollment' Courses in High School?" CCRC: Community College Research Center. Herndon, VA: National Student Clearinghouse Research Center.

Kuh, George D. 2008. High-Impact Educational Practices: What They Are, Who Has Access to Them, and Why They Matter. Washington, DC: Association of American Colleges and Universities.

Kveven, Ardi. 2016. "The Impact of a Research Vessel on Student Understanding of the Salish Sea." Poster/Talk Salish Sea
Ecosystem Conference, Vancouver, BC. Accessed April 1, 2021. https://cedar.wwu.edu/ssec/2016ssec/engagement/12/

Kveven, Ardi, and Josh Searle. 2008. "Ocean Research College Academy." Current: The Journal of Marine Education 24(3): $24-28$.

Kveven, Ardi, and Josh Searle. 2013. "Interdisciplinary, CohortBased Undergraduate Research at the Ocean Research College Academy." CUR Quarterly 34(4): 3-9.

National Research Council. 2000. How People Learn: Brain, Mind, Experience, and School: Expanded Edition. Washington, DC: National Academies Press. doi: 10.17226/9853

Ocean Research College Academy (ORCA). n.d.a "Possession Sound Student Showcase and Talks 2020 Virtual Event." Accessed April 1, 2021. https://sites.google.com/view/possessionsoundstudentshowcase

Ocean Research College Academy (ORCA). n.d.b "ORCA Water Quality Stations.” Accessed April 9, 2021. https://wqdatalive. com/public/609

Weston, Timothy, and Sandra Laursen. 2017. "The Undergraduate Research Student Self-Assessment (URSSA): Validation for Use in Program Evaluation." CBE-Life Sciences Education 14(3): 1-10. doi: 10.1187/cbe.14-11-0206

\section{Ardi Kveven}

Everett Community College, orca@everettcc.edu

Ardi Kveven is the founder and executive director of the Ocean Research College Academy (ORCA) at Everett Community College. Kveven earned a bachelor's degree in biology with a marine emphasis, along with a teaching certificate, from the University of Washington. She holds a master's degree in science education from Western Washington University and a US Coast Guard 100-ton master's license. She taught marine science and oceanography from high school to college level for 14 years. Kveven also serves as a board member for the SeaDoc Society, which works to protect the health of marine wildlife and their ecosystems through science and education. 